\title{
Construction of a nomogram predicting the overall survival of patients with distantly metastatic non-small-cell lung cancer
}

This article was published in the following Dove Press journal: Cancer Management and Research

\author{
Jianqing Deng \\ Zhipeng Ren \\ Jiaxin Wen \\ Bo Wang \\ Xiaobin Hou \\ Zhiqiang Xue \\ Xiangyang Chu
}

Department of Thoracic Surgery, Chinese PLA General Hospital,

Beijing, People's Republic of China
Correspondence: Xiangyang Chu Department of Thoracic Surgery, Chinese PLA General Hospital, 28 Fuxing Road, Haidian District, Beijing 100853, People's Republic of China

Tel $+86 \quad 17343090236$

Fax +86 I73 43090236

Email drchu30I@aliyun.com
Purpose: This study aimed to establish a nomogram to predict the overall survival (OS) of the general non-small-cell lung cancer (NSCLC) patients with distant metastasis.

Patients and methods: We investigated Surveillance, Epidemiology, and End Results database for NSCLC patients with distant metastasis diagnosed between 2010 and 2014. Statistically significant prognostic factors were identified using uni- and multivariable Cox regression analyses. A nomogram incorporating these prognostic factors was developed and evaluated by the Harrell's concordance index (C-index), calibration plots, and risk group stratifications. Results: We finally included 18,209 patients for analysis. These patients were divided into two groups, 14,567 cases for the training cohort and 3,642 for the validation cohort. Marital status, sex, race, age, histology, $\mathrm{T}$ stage, $\mathrm{N}$ stage, histological differentiation, bone metastasis, brain metastasis, liver metastasis, with M1a disease, surgery of primary cancer, and chemotherapy were identified as the prognostic factors of the OS and integrated to construct the nomogram. The nomogram had a C-index of 0.704 (95\% CI: 0.699-0.709) in the training set and 0.699 (95\% CI: 0.689-0.709) in the validation set. The calibration curves for 1- and 2-year OS in the training and validation sets showed acceptable agreement between the predicted and observed survival. Also, the nomogram was capable of stratifying patients into different risk groups within the patients who presented with bone, liver, or brain metastasis, as well as in each T, N stage, respectively.

Conclusion: A nomogram was established and validated to predict individual prognosis for the general patients with distantly metastatic NSCLC. Global prospective data with the latest TNM classification and more comprehensive prognostic factors are needed to improve this model.

Keywords: nomogram, metastatic lung cancer, SEER, prognosis, overall survival, prediction

\section{Introduction}

Lung cancer is one of the most common malignancies as well as the leading cause of cancer-related death both in males and females worldwide. ${ }^{1}$ Non-small-cell lung cancer (NSCLC) constitutes for about $80 \%$ of all lung cancer cases. About $55 \%$ of NSCLC patients present with distant metastasis at diagnosis and have a poor prognosis with a median survival time of $8-9$ months, ${ }^{2}$ despite medical progresses that have been made. In reality, metastatic lung cancer is a heterogeneous disease with various prognoses, ${ }^{3}$ which are affected by physical conditions of patients, such as age, sex, marital status, performance status as well as the TN stage, pathological or genotype characteristics, type of metastatic organ, number of metastatic sites, and medical treatments. ${ }^{2-8}$ Estimating prognosis of every patient accurately may benefit patients and doctors alike in all aspects of decision-making. ${ }^{9}$ The TNM stage released 
by International Association for the Study of Lung Cancer International Staging Project is widely accepted as a tool to predict the prognosis of patients and had been updated to the eighth edition. The eighth TNM stage took the number of metastatic sites into consideration and divided the cases with distant metastasis into M1b (single metastatic site) and M1c (multiple metastatic sites) subgroups. However, different metastatic organs are associated with different prognosis, and it ignores patients' physical condition, ${ }^{7,9}$ pathological or genotype characteristics, and treatments. Therefore, it is still difficult to predict individual prognosis of metastatic lung cancer precisely and accurately by this tool.

Nomogram is a commonly feasible tool to predict disease prognostication of patients. ${ }^{9}$ In recent decades, several nomograms have been developed for metastatic NSCLC patients with brain metastasis, ${ }^{10}$ or treated with chemotherapy, ${ }^{3,6}$ but no nomogram is constructed for the general distantly metastatic NSCLC cohort. In addition, EGFR-tyrosine kinase inhibitors (EGFR-TKIs) have been widely used since 2010, ${ }^{11}$ which would change the prognosis of distantly metastatic NSCLC. Therefore, the present study aimed to develop and validate a novel nomogram for this cohort by examining the cases diagnosed between 2010 and 2014 from the Surveillance, Epidemiology, and End Results (SEER) database, which covers $34.6 \%$ of the US population. ${ }^{12}$

\section{Patients and methods}

\section{Study population and data processing}

In this study, data were extracted from the SEER program (www.seer.cancer.gov) SEER*Stat Database: IncidenceSEER 18 Regs Custom Data (with additional treatment fields), Nov 2017 Sub (1973-2015 varying)-Linked to County Attributes-Total US, 1969-2016 Counties, National Cancer Institute, DCCPS, Surveillance Research Program, released in April 2018, based on the November 2017 submission using the SEER*Stat software (version 8.3.5). SEER research data are publicly available, and we obtained the permission from the SEER program to access the research data (username: dengji). Informed consent was not required for this study. The inclusion and exclusion criteria are listed as follows:

\section{Inclusion criteria}

1. Lung cancer patients were pathologically confirmed (Site codes: C34.0, C34.1, C34.2, C34.3, C34.8, and C34.9) to have pathological types of NSCLC (histologic codes: 8010, 8012, 8013, 8020, 8046, 8050, 8052, 8070-8078, $8140,8141,8143,8147,8250-8255,8260,8310,8430$,
$8480,8481,8490,8560$, and 8570-8575) diagnosed from 2010 to 2014.

2. Patients had at least one distant organ metastasis (SEER code: at least one of CS Mets at dx-bone, brain, or liver code was "Yes", there was no information about adrenal or renal metastasis)

3. Lung cancer was the first and only primary cancer diagnosis.

\section{Exclusion criteria}

1. Diagnosis was obtained through death certificate or autopsy.

2. Patients had missing or incomplete information about marital status, race, bone, brain, liver metastasis, surgery of primary cancer, or radiation.

3. Survival time was 0 month.

4. There existed unknown detailed information on accompanied metastasis information (CS Mets at $\mathrm{dx}$ code was 26, 70, and 75).

The following demographic, clinicopathological, and follow-up variables, including marital status, race, age, histology, tumor grade, American Joint Committee on Cancer (AJCC) $\mathrm{T}$ and $\mathrm{N}$ stage, primary site, laterality, bone metastasis, brain metastasis, liver metastasis, CS Mets at dx code, surgery of primary cancer, radiation, chemotherapy, vital status recode, and survival time were collected from the SEER program. According to the Collaborative Stage Data Collection System Coding Instructions, Version 02.05 , the CS Mets at $\mathrm{dx}$ code: 15-25, 32, 33, 36, 38, 41-43, 52, 53 indicate the presence of separate tumor nodule(s) in a contralateral lobe, malignant pleural or pericardial effusion, or tumor involved with pleural or pericardial nodule(s). ${ }^{13}$ We defined a new item "With M1a". If the CS Mets at dx code of a patient was coded as one of them, his/her "With M1a" item would be coded as "Yes". Age is a continuous variable and was transformed into categorical variables according to the cutoff values determined by the X-tile software (https://medicine.yale.edu/lab/rimm/ research/software.aspx). The software can divide continuous variable into several subgroups with the largest chi-squared log-rank value and the minimum $P$-value rationally. ${ }^{14}$ Surgery of primary cancer and radiation therapy was divided into two categories ("yes" or "no"). Overall survival (OS) was defined as the time from diagnosis to death despite the causes.

\section{Statistical analysis}

The cases that we finally included were assigned randomly into the training and validation sets in a $4: 1$ ratio by the digital method. We performed a descriptive analysis of 
the demographic and clinicopathological features of the included patients in training and validation sets. At the same time, we calculated the median survival time $(95 \% \mathrm{CI})$ for each subgroup using the Kaplan-Meier analysis. In the training cohort, prognostic risks of the OS were identified using the unadjusted univariable Cox regression analysis. Variables that reached statistical significance $(P<0.05)$ were involved into multivariable analyses. According to the results of the Cox proportional hazards model, variables that remained statistically significance $(P<0.05)$ were incorporated to construct the nomogram by $\mathrm{R}$ software version 3.3.3 (Institute for Statistics and Mathematics, Vienna, Austria; www.r-project.org) with the "rms" and "survival" package. The nomogram adopted the 1- and 2-year OS as the endpoints. We used the Harrell's concordance index (C-index) with a $95 \% \mathrm{CI}$ to evaluate the discriminative ability of the nomogram by 1,000 bootstraps resamples for internal validation in the training cohort and external validation in the validation set, respectively. We developed calibration blots in the two sets to visualize the agreement between the predicted and observed 1- and 2-year OS to assess the predicted accuracy of the nomogram. In addition, patients in the validation set were assigned into different risk groups according to quartile of prognostic scores in training cohort. Survival curves for different risk groups in the validation set were generated by the Kaplan-Meier analysis and compared using the log-rank test in order to investigate the discriminate ability of the nomogram. Two-sided $P$-values $<0.05$ were considered as statistically significance. All statistical analysis procedures were performed using SPSS 23.0 (SPSS Inc., Chicago, IL, USA).

\section{Results}

\section{Baseline clinicopathological features}

Finally, a total of 18,209 cases that met our criteria were extracted from the SEER database. The details of caseselection procedures are demonstrated in Figure 1. The entire cohort was randomly allocated into two groups, 14,567 cases in the training cohort and 3,642 cases in the validation cohort, respectively. The demographic and clinicopathological features of the patients in the two cohorts are shown in Table 1, as well as the OS $(95 \% \mathrm{CI})$ of each subgroup. The median age (25th-75th percentile) of the training set at diagnosis was 64 (57-72) years. Age is a continuous variable and was transformed into three categories according to the cutoff value: Min-61, 62-73, and 74-Max, which were determined by $\mathrm{x}$-tiles with the maximum Chi-squared log-rank value. There were $58.84 \%, 58.04 \%, 19.79 \%$, and $25.04 \%$ of the patients who presented with bone, brain, liver metastasis, and M1a diseases at diagnosis, respectively. The median OS (25-75

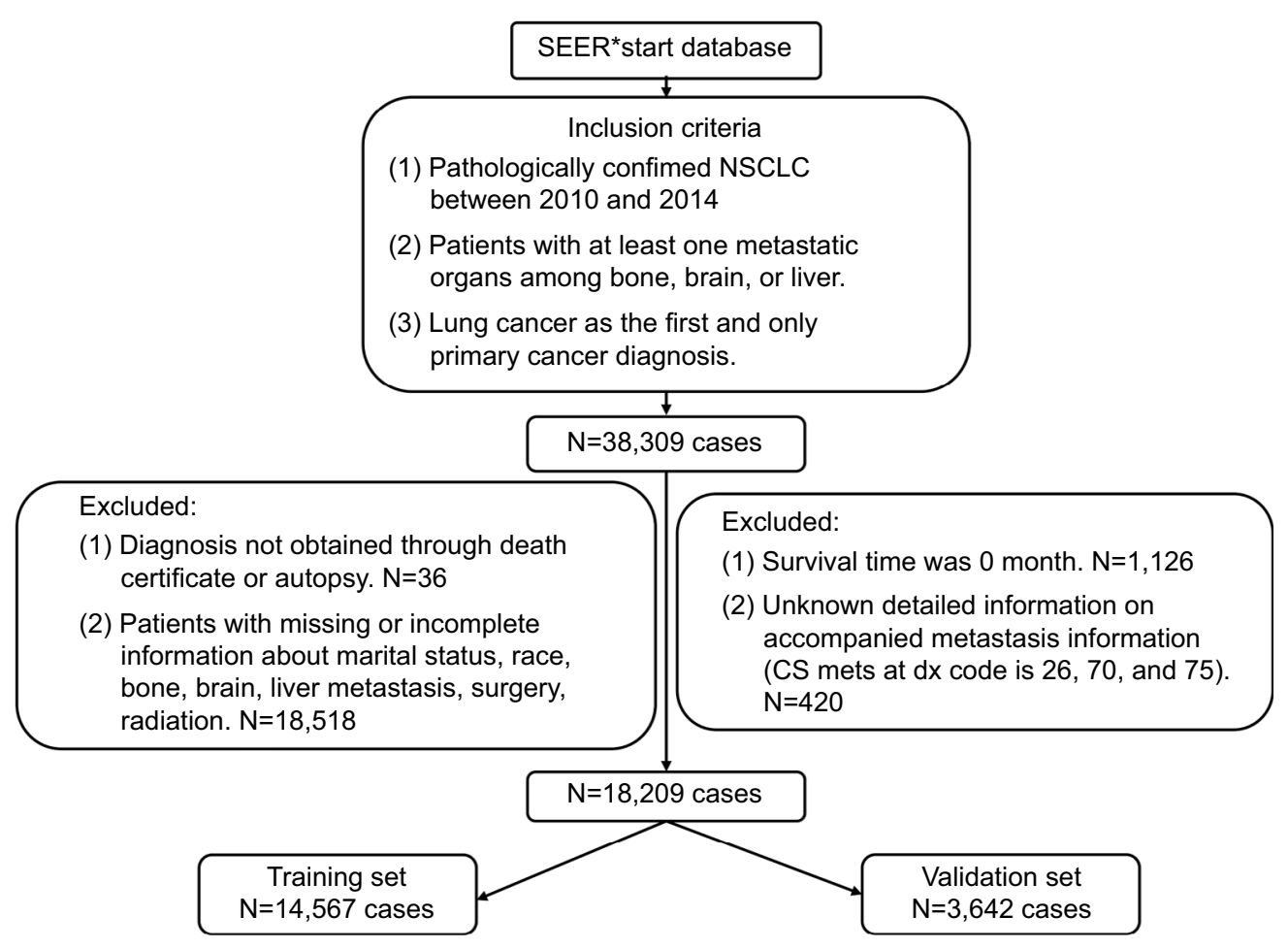

Figure I The flowchart of cases selection.

Abbreviations: NSCLC, non-small-cell lung cancer; SEER, Surveillance, Epidemiology, and End Results 
Table I Demographic and clinicopathological characteristics of the training cohort and validation cohort

\begin{tabular}{|c|c|c|c|c|c|c|}
\hline \multirow{3}{*}{$\begin{array}{l}\text { Demographic or } \\
\text { clinicopathological } \\
\text { characteristics }\end{array}$} & \multicolumn{3}{|c|}{ Training set $(N=\mid 4,567)$} & \multicolumn{3}{|c|}{ Validation set $(\mathrm{N}=3,642)$} \\
\hline & \multirow{2}{*}{$\begin{array}{l}\text { No. of } \\
\text { patients (\%) }\end{array}$} & \multicolumn{2}{|c|}{ OS (months) } & \multirow{2}{*}{$\begin{array}{l}\text { No. of } \\
\text { patients (\%) }\end{array}$} & \multicolumn{2}{|c|}{ OS (months) } \\
\hline & & Median & $95 \% \mathrm{Cl}$ & & Median & $95 \% \mathrm{Cl}$ \\
\hline \multicolumn{7}{|l|}{ Sex } \\
\hline Male & $8,126(55.78)$ & 5 & $4.84-5.16$ & $1,960(53.82)$ & 5 & $4.66-5.34$ \\
\hline Female & $6,44 \mathrm{I}(44.22)$ & 6 & $5.75-6.26$ & $\mathrm{I}, 682(46.18)$ & 6 & $5.52-6.48$ \\
\hline \multicolumn{7}{|l|}{ Marital status at diagnosis } \\
\hline Married & $8,162(56.03)$ & 6 & $5.79-6.20$ & I,995 (54.78) & 6 & $5.56-6.45$ \\
\hline Unmarried & $6,405(43.97)$ & 5 & $4.82-5.18$ & $\mathrm{I}, 647(45.22)$ & 5 & $4.67-5.33$ \\
\hline \multicolumn{7}{|l|}{ Race } \\
\hline White & II,405 (78.29) & 5 & $4.86-5.14$ & $2,8 \mid 5(8 \mid .3 I)$ & 5 & $4.72-5.28$ \\
\hline Black & $\mathrm{I}, 893(\mathrm{I} 3.00)$ & 5 & $4.66-5.34$ & $486(13.34)$ & 5 & $4.40-5.61$ \\
\hline Others & $\mathrm{I}, 269(8.7 \mathrm{I})$ & 9 & $8.14-9.86$ & $34 I(9.36)$ & II & $8.63-13.37$ \\
\hline \multicolumn{7}{|l|}{ Age at diagnosis, years } \\
\hline$\leq 61$ & $5,873(40.32)$ & 7 & $6.74-7.26$ & $\mathrm{I}, 466(40.25)$ & 7 & $6.39-7.61$ \\
\hline $62-73$ & $5,614(38.54)$ & 5 & $4.80-5.20$ & $\mathrm{I}, 405(38.58)$ & 5 & $4.60-5.40$ \\
\hline$\geq 74$ & $3,080(21.14)$ & 4 & $3.83-4.17$ & $711(19.52)$ & 4 & $3.66-4.34$ \\
\hline \multicolumn{7}{|l|}{ Histology } \\
\hline Adenocarcinoma & $9,420(64.67)$ & 6 & $5.80-6.20$ & $2,389(65.60)$ & 6 & $5.58-6.42$ \\
\hline Squamous cell carcinoma & $2,369(16.26)$ & 4 & $3.75-4.26$ & $565(I 5.5 I)$ & 4 & $3.44-4.56$ \\
\hline Large cell carcinoma & $38 I(2.62)$ & 4 & $3.29-4.71$ & $93(2.55)$ & 4 & $3.06-4.94$ \\
\hline Others & $2,397(16.46)$ & 4 & $3.7 I-4.29$ & $595(16.34)$ & 4 & $3.43-4.57$ \\
\hline \multicolumn{7}{|l|}{ Grade } \\
\hline $\mathrm{I}$ & $236(1.62)$ & 9 & $7.00-11.00$ & $60(1.65)$ & 8 & $4.20-11.80$ \\
\hline II & $\mathrm{I}, 538(10.56)$ & 7 & $6.47-7.53$ & $359(9.86)$ & 6 & $4.58-7.42$ \\
\hline III & $3,865(26.53)$ & 5 & $4.77-5.23$ & $\mathrm{I}, 016(27.90)$ & 5 & $4.55-5.45$ \\
\hline IV & $176(1.2)$ & 4 & $3.38-4.62$ & $31(0.85)$ & 7 & $3.77-10.23$ \\
\hline Unknown & $8,752(60.08)$ & 5 & $4.84-5.17$ & $2,176(59.75)$ & 5 & $4.67-5.33$ \\
\hline \multicolumn{7}{|l|}{ T stage } \\
\hline TO, TI & $\mathrm{I}, 864(\mathrm{I} 2.80)$ & 8 & $7.44-8.56$ & 487 (I3.37) & 8 & $7.15-8.85$ \\
\hline $\mathrm{T} 2$ & $3,748(25.73)$ & 6 & $5.70-6.30$ & $909(24.96)$ & 6 & $5.33-6.67$ \\
\hline T3 & $3,319(22.78)$ & 5 & $4.74-5.26$ & $813(22.32)$ & 5 & $4.58-5.42$ \\
\hline $\mathrm{T} 4$ & $4,188(28.75)$ & 5 & $4.76-5.24$ & $\mathrm{I}, 080(29.65)$ & 4 & $3.59-4.41$ \\
\hline$T x$ & $1,448(9.94)$ & 5 & $4.62-5.38$ & $353(9.69)$ & 4 & $3.38-4.62$ \\
\hline \multicolumn{7}{|l|}{$\mathrm{N}$ stage } \\
\hline No & $3,246(22.28)$ & 7 & $6.6 I-7.39$ & $784(21.53)$ & 7 & $6.20-7.80$ \\
\hline $\mathrm{NI}$ & $1,229(8.44)$ & 6 & $5.39-6.61$ & $293(8.05)$ & 5 & $4.05-5.95$ \\
\hline N2 & $6,675(45.82)$ & 5 & $4.82-5.18$ & $\mathrm{I}, 656(45.47)$ & 5 & $4.63-5.37$ \\
\hline N3 & 2,837 (19.48) & 5 & $4.7 I-5.29$ & 74I (20.35) & 5 & $4.50-5.50$ \\
\hline $\mathrm{Nx}$ & $580(3.98)$ & 4 & $3.33-4.67$ & $168(4.61)$ & 4 & $3.30-4.69$ \\
\hline \multicolumn{7}{|l|}{ Primary site } \\
\hline Main bronchus & $67 \mid(4.60)$ & 4 & $3.47-4.53$ & $152(4.17)$ & 5 & $3.43-6.58$ \\
\hline Lobe & II,883 (8I.57) & 6 & $5.84-6.16$ & $3,005(82.5 \mathrm{I})$ & 5 & $4.72-5.28$ \\
\hline Overlapping lesion of lung & $136(0.93)$ & 5 & $3.70-6.31$ & $27(0.74)$ & 6 & $3.46-8.54$ \\
\hline $\begin{array}{l}\text { Lung, not otherwise } \\
\text { specified }\end{array}$ & I,877 (I2.89) & 5 & $4.64-5.36$ & $458(12.58)$ & 5 & $4.35-5.65$ \\
\hline \multicolumn{7}{|l|}{ Laterality } \\
\hline Left & $5,732(39.35)$ & 5 & $4.77-5.23$ & $\mathrm{I}, 436(39.43)$ & 6 & $5.54-6.46$ \\
\hline Right & $8,028(55.1 \mathrm{I})$ & 5 & $4.8 I-5.19$ & $2,019(55.44)$ & 5 & $4.65-5.35$ \\
\hline Others & $807(5.54)$ & 5 & $4.38-5.62$ & $187(5.13)$ & 5 & $3.97-6.03$ \\
\hline \multicolumn{7}{|l|}{ With Mla } \\
\hline Yes & $3,648(25.04)$ & 4 & $3.76-4.24$ & $950(26.08)$ & 4 & $3.52-4.48$ \\
\hline No & $10,919(74.96)$ & 6 & $5.82-6.18$ & $2,692(73.92)$ & 6 & $5.63-6.37$ \\
\hline
\end{tabular}


Table I (Continued)

\begin{tabular}{|c|c|c|c|c|c|c|}
\hline \multirow{3}{*}{$\begin{array}{l}\text { Demographic or } \\
\text { clinicopathological } \\
\text { characteristics }\end{array}$} & \multicolumn{3}{|c|}{ Training set $(\mathrm{N}=14,567)$} & \multicolumn{3}{|c|}{ Validation set $(\mathrm{N}=3,642)$} \\
\hline & \multirow{2}{*}{$\begin{array}{l}\text { No. of } \\
\text { patients (\%) }\end{array}$} & \multicolumn{2}{|c|}{ OS (months) } & \multirow{2}{*}{$\begin{array}{l}\text { No. of } \\
\text { patients (\%) }\end{array}$} & \multicolumn{2}{|c|}{ OS (months) } \\
\hline & & Median & $95 \% \mathrm{Cl}$ & & Median & $95 \% \mathrm{Cl}$ \\
\hline \multicolumn{7}{|l|}{ Brain metastasis } \\
\hline Yes & $8,460(58.08)$ & 6 & $5.80-6.20$ & $2,143(58.84)$ & 5 & $4.59-5.41$ \\
\hline No & 6,107 (4I.92) & 5 & $4.82-5.18$ & $\mathrm{I}, 499(4 \mathrm{I} .16)$ & 5 & $4.62-5.38$ \\
\hline \multicolumn{7}{|l|}{ Liver metastasis } \\
\hline Yes & 2,883 (19.79) & 4 & $3.8 I-4.19$ & $680(18.67)$ & 3 & $2.68-3.32$ \\
\hline No & $\mathrm{II}, 684(80.2 \mathrm{I})$ & 6 & $5.83-6.17$ & $2,962(81.33)$ & 6 & $5.64-6.36$ \\
\hline \multicolumn{7}{|l|}{ Radiation } \\
\hline Yes & $14,304(98.19)$ & 5 & $4.86-5.14$ & $3,582(98.35)$ & 5 & $4.74-5.26$ \\
\hline No & $263(1.80)$ & 2 & $1.66-2.35$ & $60(1.65)$ & 2 & $1.37-2.63$ \\
\hline \multicolumn{7}{|l|}{ Chemotherapy } \\
\hline Yes & $9,186(63.06)$ & 8 & $7.79-8.21$ & $2,330(63.98)$ & 8 & $7.56-8.44$ \\
\hline No/Unknown & $5,38 I(36.94)$ & 2 & $1.92-2.08$ & $\mathrm{I}, 3 \mathrm{I} 2(36.02)$ & 2 & $1.84-2.16$ \\
\hline \multicolumn{7}{|l|}{ Surgery } \\
\hline Yes & $359(2.46)$ & 13 & $11.10-14.90$ & $95(2.6 \mathrm{I})$ & 13 & $9.95-16.05$ \\
\hline No & $14,208(97.54)$ & 5 & $4.87-5.13$ & 3,547 (97.39) & 5 & $4.75-5.25$ \\
\hline
\end{tabular}

percentile) was only $5(2-12)$ months. The 1 - and 2-year OS survival rate was only $23.8 \%$ and $8.0 \%$, respectively.

\section{Independent prognostic factors in the training set}

We performed univariable unadjusted Cox analysis to the following variables: marital status (married vs unmarried), race (White vs Black vs others), sex (male vs female), age ( $\leq 61$ vs $62-73$ vs $\geq 74$ years), histology type (adenocarcinoma [ADC] vs squamous cell carcinoma vs large cell carcinoma vs others), tumor sites (main bronchus vs lobe vs overlapping lesion of lung vs lung, not otherwise specified), laterality (left vs right vs others), T stage (T0, T1 vs T2 vs T3 vs T4 vs Tx), N stage (N0 vs N1 vs N2 vs N3 vs Nx), histological differentiation (grade I vs grade II vs grade III vs grade IV vs grade $\mathrm{X}$ ), bone metastasis (yes vs no), brain metastasis (yes vs no), liver metastasis (yes vs no), with M1a (yes vs no), surgery of primary cancer (yes vs no), radiation (yes vs no), and chemotherapy (yes vs no/unknown) using the training cohort. All aforementioned variables except laterality $(P=0.821)$ were identified as statistically significant prognostic factors (all $P<0.001$ ) (Table S1). These prognostic factors were then included in the multivariable analysis, and we observed that radiation therapy was not significantly associated with the OS $(P=0.143)$ (Table S1). During the analysis process, we found that some subgroups of patients had similar OS, we thereby combined these subgroups as one category in the multivariable analysis, including White and Black populations, T2, T3, T4, and Tx, grade I and grade II, as well as grade III and grade X, N1, N2, N3, and Nx. After combining these subgroups, we conducted the multivariable analysis again. The results showed that all of these factors were still significantly associated with OS. All factors were then incorporated to develop the nomogram. However, we found that four subgroups of tumor sites scored 0 , therefore, these variables were removed from the following analysis. After that, we performed the multivariable analysis again, and the remaining 14 variables remained the prognostic factors of OS (Table 2).

\section{Nomogram development and validation}

We then constructed a nomogram integrating these prognostic factors using the training cohort (Figure 2). As is shown in the nomogram, chemotherapy made the largest contribution to the prognosis, followed by surgery of primary cancer, interestingly. Race, tumor grade, presence of liver, bone metastasis, age, T stage, $\mathrm{N}$ stage, and histology, which showed moderate impacts on the OS, while the presence of M1 a disease, brain metastasis, sex, and marital status made the modest difference to the prognosis. Each negative subtype within these variables was assigned a score (Table 3 ). By adding up these scores according to a patient's condition, the total score was obtained. Then, the total score was located on the total point line, and a straight line could be drawn to estimate the patient's probability of 1- and 2-year OS. The nomogram had a C-index of 0.704 (95\% CI: 0.699-0.709) in the training set and 0.699 (95\% CI: $0.689-0.709)$ in the validation set. The calibration curves for 1- and 2-year OS 
Table 2 Results of the multivariable Cox regression analysis after combining the subgroups with similar OS

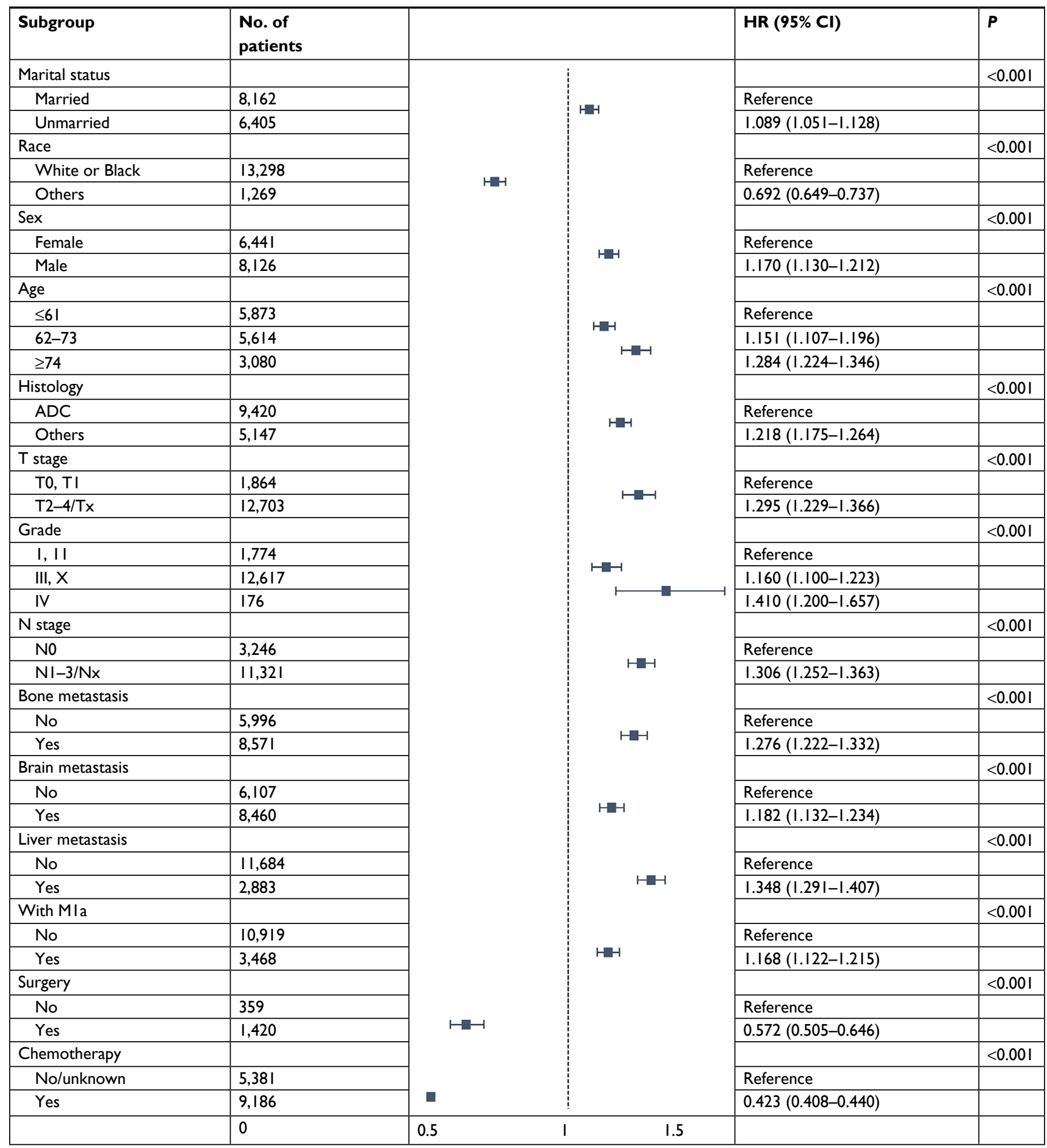

Abbreviations: $O S$, overall survival; $A D C$, adenocarcinoma.

showed acceptable agreement between the predicted and actual survival in both cohorts (Figures 3 and 4).

\section{Risk stratifications}

We added the total score for every patient in the training set, and then sorted the patients according to the scores to get the quartile of prognosis scores: Min-224, 225-259, 260-311, and 312-Max. Each risk group represented a distinct prognosis. We observed significant distinctions between the Kaplan-Meier curves $(P=0.00)$ within overall patients or patients with brain, liver, bone metastasis, as well as T0, T1 stage, T2-4, Tx stage, N0 stage, and N1-3, Nx stage, 


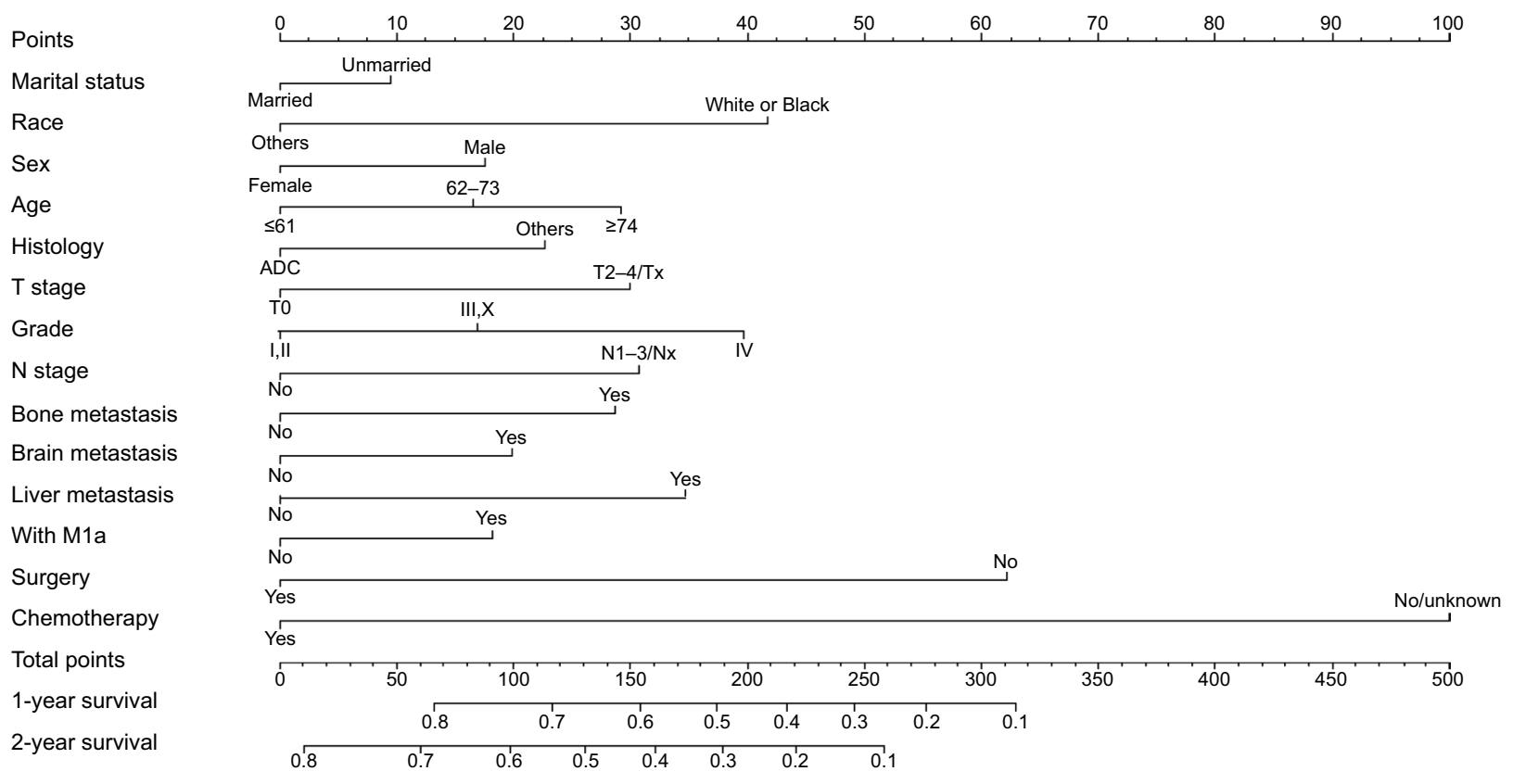

Figure 2 Nomogram for predicting I- and 2-year OS of NSCLC patients with distant organ metastasis ("Surgery" refers to surgery to the primary cancer site). Abbreviations: ADC, adenocarcinoma; NSCLC, non-small-cell lung cancer; OS, overall survival.

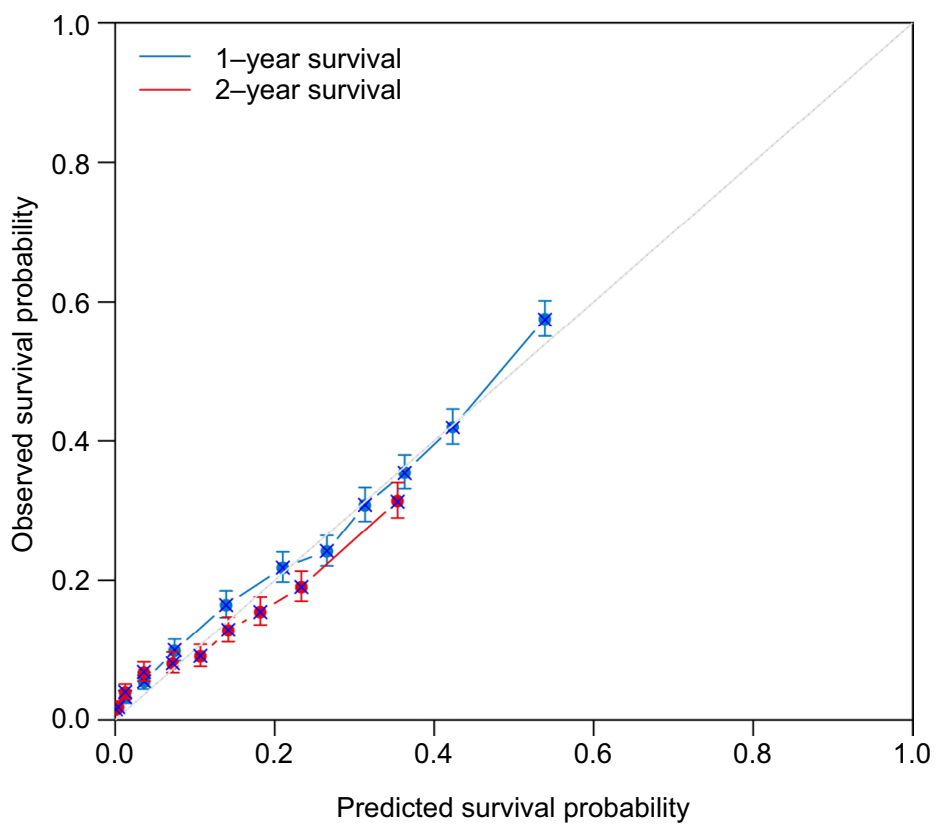

Figure 3 Calibration plots of the internal training cohort.

respectively, after applying the cutoff values to divide the patients in the validation cohort, as shown in Figures 5 and 6.

\section{Discussion}

In the current study, we established a nomogram to predict the prognosis of general distantly metastatic NSCLC patients using the data retrieved from the SEER database. A total of 18,209 cases were included, and 14 significant prognosis factors that represent demographic, pathological, and treatment data were identified by conducting uni- and subsequent multivariable analysis in the training set and then integrated to construct the nomogram. The validation showed that the nomogram is of acceptable discrimination ability with a C-index of 0.704 (95\% CI: 0.699-0.709) in the training set and 0.699 (95\% CI: 0.689-0.709) in the validation set. As is shown in the calibration blots, the nomogram can predict 


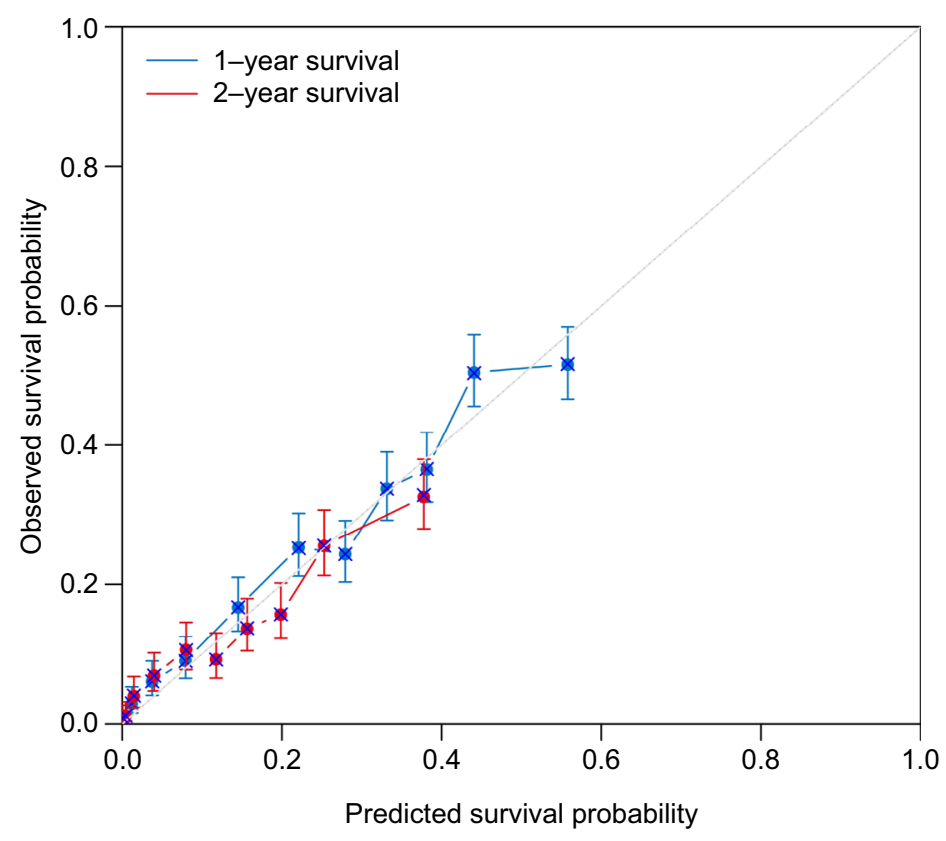

Figure 4 Calibration plots of the external validation cohort.

Table 3 Scores of every subgroup within each variable

\begin{tabular}{|l|l|l|l|}
\hline Variables & Points & Variables & Points \\
\hline Marital status & & Grade & \\
\hline Married & 0 & I, II & 0 \\
\hline Unmarried & 9 & III, X & 17 \\
\hline Race & & IV & 40 \\
\hline White or Black & 42 & Bone metastasis & \\
\hline Others & 0 & No & 0 \\
\hline Sex & & Yes & 29 \\
\hline Female & 0 & Brain metastasis & \\
\hline Male & 17 & No & 0 \\
\hline Age & & Yes & 20 \\
\hline$\leq 6 I$ & 0 & Liver metastasis & \\
\hline $62-73$ & 17 & No & 0 \\
\hline$\geq 74$ & 29 & Yes & 35 \\
\hline Histology & & With Mla & \\
\hline ADC & 0 & No & 0 \\
\hline Others & 23 & Yes & 18 \\
\hline T stage & & Surgery & \\
\hline T0, TI & 0 & No & 62 \\
\hline T2-4/Tx & 30 & Yes & 0 \\
\hline N stage & & Chemotherapy & \\
\hline N0 & 0 & No/unknown & 100 \\
\hline NI-3/Nx & 31 & Yes & 0 \\
\hline Ab & & \\
\hline
\end{tabular}

Abbreviation: $A D C$, adenocarcinoma.

1- and 2-year OS accurately. The nomogram was also capable of stratifying patients into different risk groups within the patients presented with bone, liver, or brain metastasis, as well as $\mathrm{T}$, $\mathrm{N}$ stages.

To the best of our knowledge, this is the first prognosis nomogram developed for general NSCLC patients with distant organ metastasis based on a large, diverse, population-based cohort that was collected from the SEER program. This nomogram can easily predict the prognosis of a patient and inform individual benefits of certain medical treatments as well as stratify the patient into different risk subgroups, which might be meaningful and informatory for clinical decision-making. For example, for the metastatic EGFR-mutated NSCLC, the National Comprehensive Cancer Network guideline recommended the EGFR-TKIs as their first-line therapy, ${ }^{15}$ among them, this nomogram can help to recognize the high-risk subgroups that may need more intensive treatments like chemotherapy at the same time. In addition, for the high-risk subgroup among the whole population determined by our nomogram, we should pay closer attention and shorten the follow-up period in order to adjust treatment methods in a timely manner according to the changes of their tumor condition. We can also give them more palliative care like psychological or sentimental support and encourage them to participate in clinical trials of anticancer drugs. Furthermore, these tools may help the designers of clinical trials to get more equivalent baselines between different study groups. It is also worth noting that the SEER database covers $34.6 \%$ of the US population, ${ }^{12}$ which, therefore, guarantees the representativeness of our nomogram and implies the potential universal application of our nomogram, which has an acceptable discrimination ability and excellent prediction accuracy. 


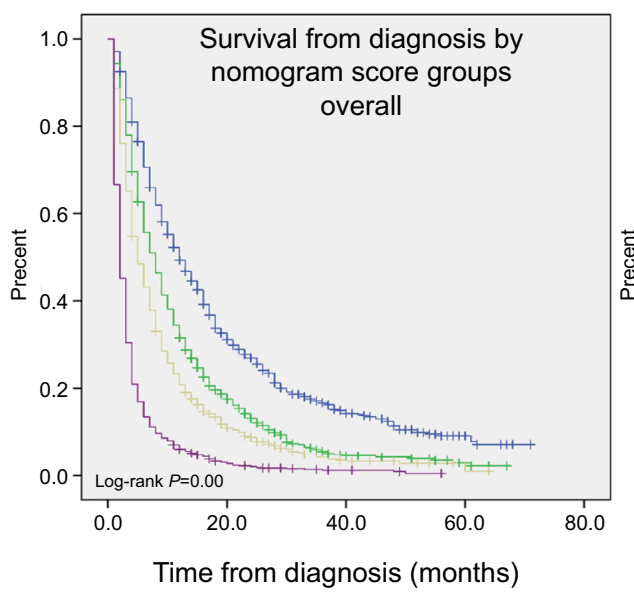

\begin{tabular}{ccc}
\hline Score & Events/N & $\begin{array}{l}\text { Median in } \\
\text { months (range) }\end{array}$ \\
\hline Min-224 & $693 / 853$ & $12(10.75,13.25)$ \\
$225-259$ & $801 / 882$ & $8(7.32,8.68)$ \\
$260-311$ & $756 / 806$ & $5(4.53,5.47)$ \\
$312-M a x$ & $1083 / 1101$ & $2(1.84,2.16)$ \\
\hline
\end{tabular}

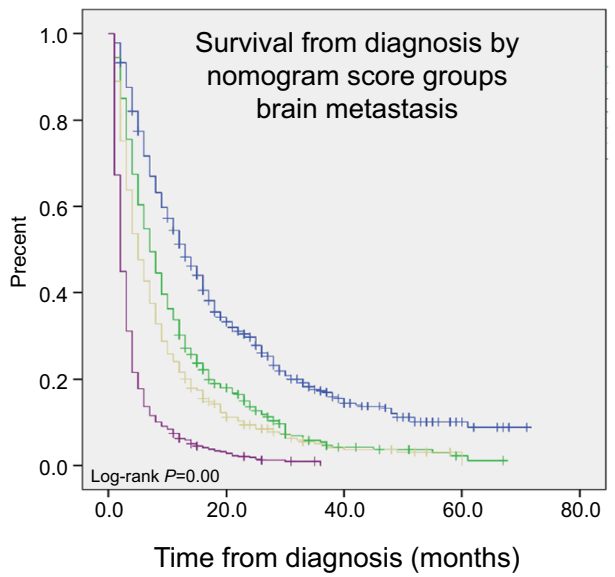

\begin{tabular}{ccc}
\hline Score & Events/N & $\begin{array}{l}\text { Median in } \\
\text { months (range) }\end{array}$ \\
\hline Min-224 & $450 / 568$ & $13(11.44,14.56)$ \\
$225-259$ & $464 / 512$ & $7(6.18,7.82)$ \\
$260-311$ & $420 / 450$ & $5(4.53,5.66)$ \\
$312-M a x$ & $604 / 613$ & $2(1.82,2.18)$ \\
\hline
\end{tabular}

Figure 5 Risk group stratification within overall patients and each metastatic site.

Notably, we did not include the NSCLC patients with stage M1a. It is because the prognosis of M1a patients is significantly better than $\mathrm{M} 1 \mathrm{~b}$ patients, and the presence with M1a disease would have a contradictory impact on M1a and M1b patients, which would result in wrong scores in M1a item of the nomogram.

Marital status, sex, race, age, histology, T stage, N stage, histological differentiation, the presence of bone metastasis,
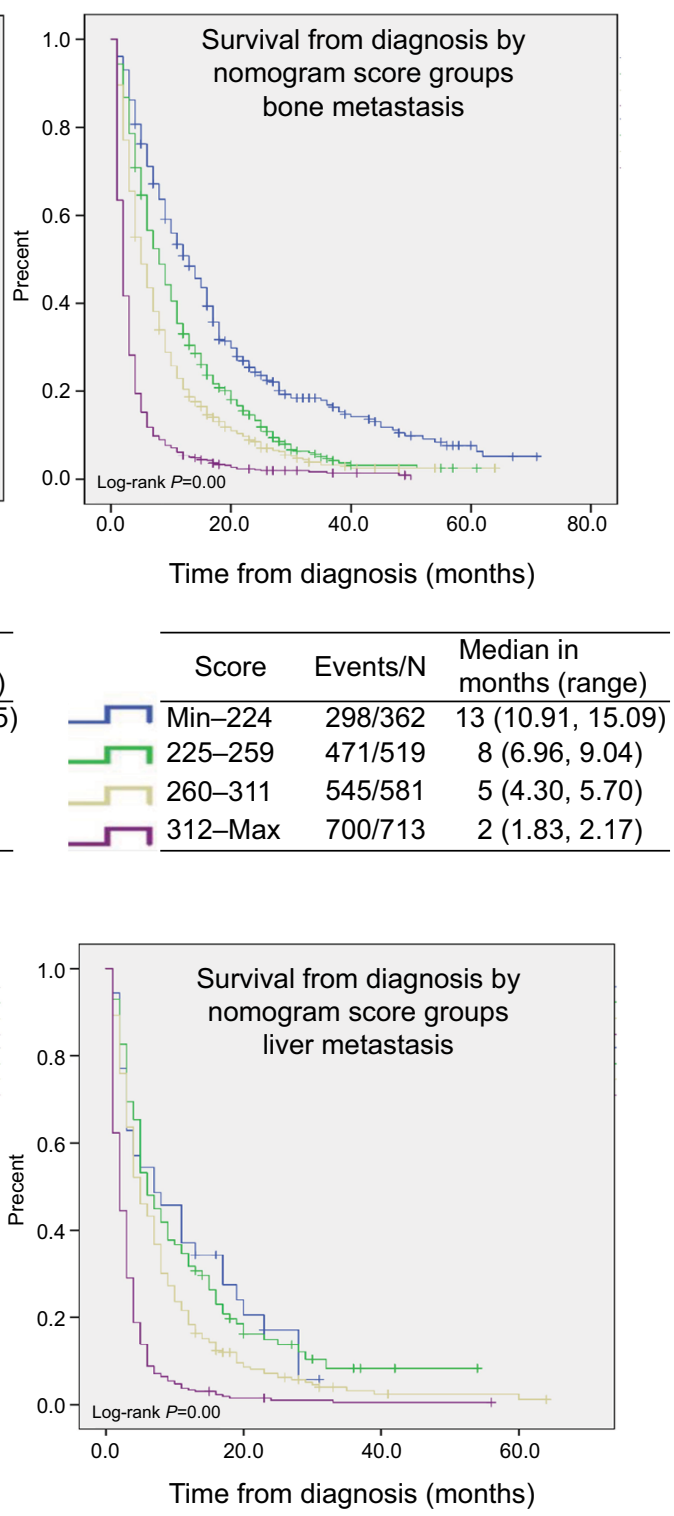

\begin{tabular}{|c|c|c|c|}
\hline & Score & Events/N & $\begin{array}{l}\text { Median in } \\
\text { months (range) }\end{array}$ \\
\hline r & Min-224 & $30 / 35$ & $7(1.21,12.80)$ \\
\hline & $225-259$ & $86 / 95$ & $6(4.55,7.45)$ \\
\hline- & $260-311$ & $239 / 250$ & $5(4.09,5.91)$ \\
\hline תـ & 312-Max & $294 / 267$ & $2(1.68,2.32)$ \\
\hline
\end{tabular}

brain metastasis, liver metastasis, M1a disease, surgery of primary cancer, and chemotherapy were identified as the prognostic factors of the OS, which was in line with the previous studies..$^{5,7,8,11,16-18}$ Among them, surgery of primary cancer could notably improve the prognosis. Thus, we analyzed the characteristics of these patients who underwent surgery and found that all of them received radiation therapy, and most of them received chemotherapy. Surgery to the 

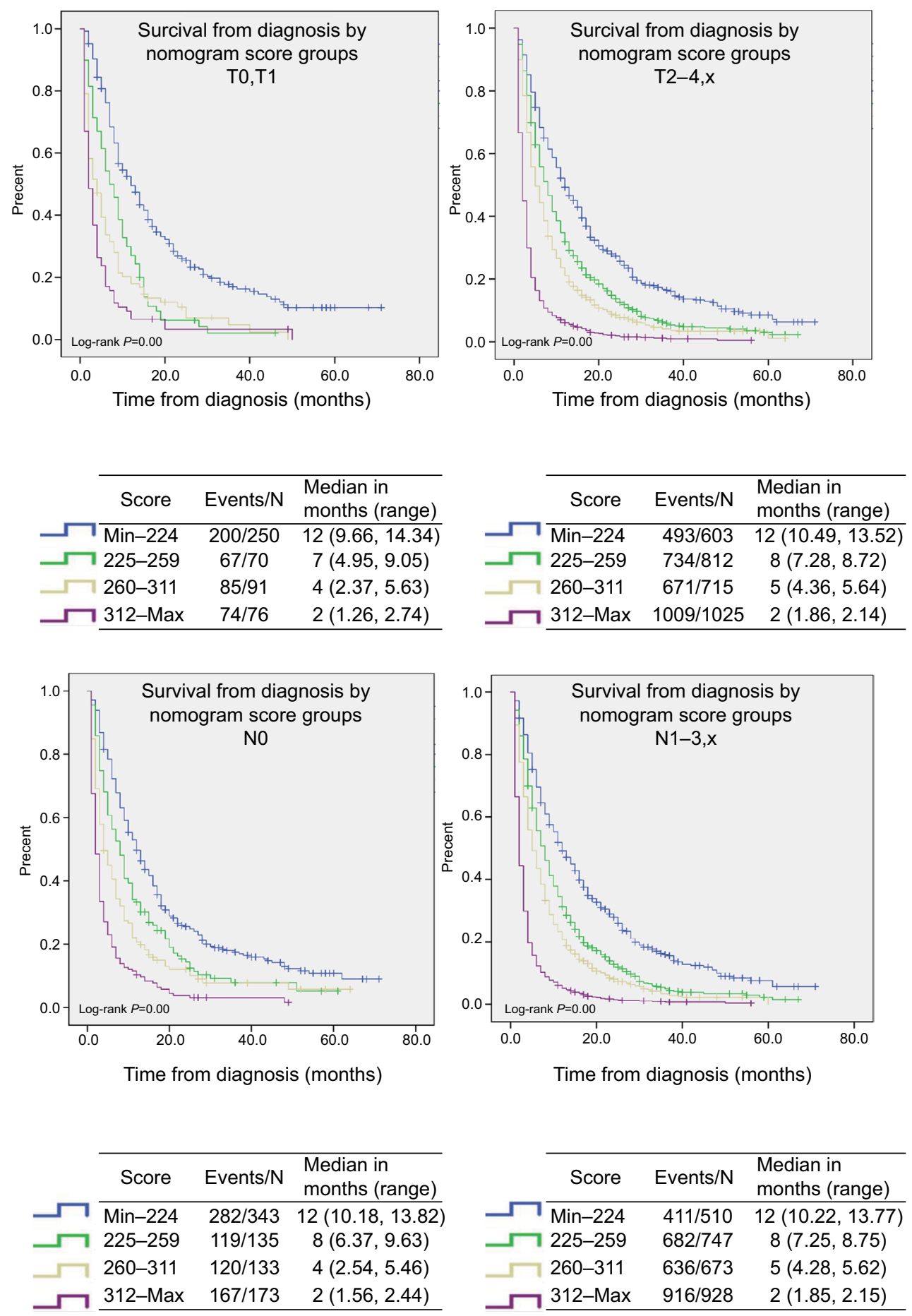

\begin{tabular}{rrc}
\hline Score & Events/N & $\begin{array}{l}\text { Median in } \\
\text { months (range) }\end{array}$ \\
\hline Min-224 & $411 / 510$ & $12(10.22,13.77)$ \\
$225-259$ & $682 / 747$ & $8(7.25,8.75)$ \\
$260-311$ & $636 / 673$ & $5(4.28,5.62)$ \\
$312-M a x$ & $916 / 928$ & $2(1.85,2.15)$ \\
\hline
\end{tabular}

Figure 6 Risk group stratification within TN stage with similar OS.

Abbreviations: TN, tumor node; OS, overall survival.

primary cancer site was treated as a part of the multimodality regimens. David et al queried the California Cancer Registry and identified 34,016 patients to make an unmatched survival analysis; they also found that the stage IV NSCLC patients who underwent surgical procedures as a part of their multimodality therapy had significantly longer median OS than these receiving non-surgical treatments (9.4-28 vs
2-10 months). ${ }^{19}$ Given the patients' favorable responses to systemic therapies like targeted therapy and immunotherapy, surgery to the primary cancer might be reconsidered as a part of multimodality therapy. Surgery can provide enough tissue to enable detailed molecular and genetic subtyping of NSCLC. ${ }^{20}$ It can also decrease patients' tumor burden and alleviate or eliminate the complications caused by tumors to 
improve patients' life quality. However, it should be noted that not all patients can benefit from surgery; whether surgical treatment should be performed on metastatic NSCLC patients should take various individual, treatment-related and disease-related factors into consideration and carefully discussed in a multidisciplinary setting. ${ }^{21}$ Moreover, surprisingly, radiation therapy did not remain significant statistically in the multivariable analysis $(P=0.143)$, which indicates that radiotherapy has a modest impact on OS, just as a previous study reported..$^{22}$ But radiation therapy is still an option of palliative care to relieve pain or complications of patients and may have potential to prolong patients' OS. $\mathrm{AD}$ was associated with the best prognosis, which might be partly interpreted by the fact that AD presents with much more EGFR gene mutations, making AD more sensitive to EGFR-TKIs. Among distant metastatic sites, liver metastasis was associated with the poorest prognosis, followed by bone metastasis, that was in high concordance with a previous research, which analyzed 17,431 lung cancer patients in Sweden. ${ }^{7}$ In a word, our nomogram included rational prognostic factors of distantly metastatic NSCLC patients.

Limitations: 1) The important prognostic factors of advanced lung cancer that were identified in previous studies, such as performance status score, body mass index, smoking status, appetite condition, genotype characteristics, serum markers, skin/adrenal metastasis, the usage of EGFR-TKIs or vascular endothelial growth factor-targeted drugs, and the detailed information of chemotherapy were not taken into consideration in this study because there were no such information provided by the SEER database..$^{2,3,6,23}$ 2) All patients were staged according to the seventh edition of the TNM classification for lung cancer; however, the coding rules on tumor extension made us difficult to restage the patients according to the latest eighth edition of the TNM classification. For example, CS extension code 600 included lung cancers extended to diaphragm, chest wall, or Pancoast cancer. Lung cancers extended to chest wall, Pancoast cancer, which are at stage T3 according to the seventh and eighth edition of the TNM classification while lung cancers extended to diaphragm is already changed to stage T4 according to the latest eighth edition of the TNM classification. ${ }^{13,24}$ As a result, we cannot determine the $\mathrm{T}$ stage of a patient with this code in the latest eighth edition of the TNM classification, which may result in inconvenience in the use of the nomogram. 3) The third limitation is the retrospective nature of the data collection from the SEER database. Moreover, overall sensitivity was $68 \%$ and $80 \%$ for chemotherapy and radiotherapy, respectively, despite a high specificity of these data. ${ }^{25} 4$ ) The nomogram is only generalized based on the data of the patients in the USA and thus, might not be representative of the patients worldwide. 5) The SEER database only provided information on metastasis to bone, brain, and liver at diagnosis, without taking the metastasis during follow-up periods into consideration. Therefore, global prospective data with the latest TNM classification and more comprehensive prognostic factors are needed to improve this model.

\section{Conclusion}

A nomogram was established and validated to predict individual prognosis for the general distantly metastatic NSCLC patients. Global prospective data with the latest TNM classification and more comprehensive prognostic factors are needed to improve this nomogram.

\section{Acknowledgments}

We thank all the members of the National Cancer Institute, who have been involved with the SEER program for their hard work in data collection.

\section{Author contributions}

Conception and design: Jianqing Deng, Xiangyang Chu. Collection and assembly of data: Jianqing Deng, Zhipeng Ren, Jiaxin Wen. Data analysis and interpretation: all authors. Manuscript writing: all authors. All authors contributed to data analysis, drafting and revising the article, gave final approval of the version to be published, and agree to be accountable for all aspects of the work.

\section{Disclosure}

The authors report no conflicts of interest in this work.

\section{References}

1. Siegel RL, Miller KD, Jemal A. Cancer statistics, 2017. CA Cancer J Clin. 2017;67(1):7-30.

2. He YY, Zhang XC, Yang JJ, et al. Prognostic significance of genotype and number of metastatic sites in advanced non-small-cell lung cancer. Clin Lung Cancer. 2014;15(6):441-447.

3. Hoang T, Xu R, Schiller JH, Bonomi P, Johnson DH. Clinical model to predict survival in chemonaive patients with advanced non-smallcell lung cancer treated with third-generation chemotherapy regimens based on eastern cooperative oncology group data. J Clin Oncol. 2005;23(1):175-183.

4. Collaud S, Stahel R, Inci I, et al. Survival of patients treated surgically for synchronous single-organ metastatic NSCLC and advanced pathologic TN stage. Lung Cancer. 2012;78(3):234-238.

5. Dai C, Ren Y, Xie D, et al. Does lymph node metastasis have a negative prognostic impact in patients with NSCLC and M1a disease? J Thorac Oncol. 2016;11(10):1745-1754.

6. Hoang T, Dahlberg SE, Sandler AB, Brahmer JR, Schiller JH, Johnson DH. Prognostic models to predict survival in non-small-cell lung cancer patients treated with first-line paclitaxel and carboplatin with or without bevacizumab. J Thorac Oncol. 2012;7(9):1361-1368.

7. Riihimäki M, Hemminki A, Fallah M, et al. Metastatic sites and survival in lung cancer. Lung Cancer. 2014;86(1):78-84. 
8. Shen H, Cao Y, Li X, et al. Surgical intervention improves survival for metastatic non-small cell lung cancer patients. Medicine. 2016;95(21):e3800.

9. Balachandran VP, Gonen M, Smith JJ, Dematteo RP. Nomograms in oncology: more than meets the eye. Lancet Oncol. 2015;16(4):e173-e180.

10. Barnholtz-Sloan JS, Yu C, Sloan AE, et al. A nomogram for individualized estimation of survival among patients with brain metastasis. Neuro Oncol. 2012;14(7):910-918.

11. Ren Y, Dai C, Zheng H, et al. Prognostic effect of liver metastasis in lung cancer patients with distant metastasis. Oncotarget. 2016;7(33):53245-53353.

12. Surveillance, Epidemiology, and End Results Program: Overview of the SEER Program. Available from: https://seer.cancer.gov/about/overview. html. Accessed November 02, 2018.

13. Collaborative Stage Data Collection System Coding Instructions, Version 02.05. Available from: http://web2.facs.org/cstage0205/lung/ Lungschema.html. Accessed November 02, 2018.

14. Camp RL, Dolled-Filhart M, Rimm DL. X-tile: a new bio-informatics tool for biomarker assessment and outcome-based cut-point optimization. Clin Cancer Res. 2004;10(21):7252-7259.

15. NCCN. Clinical practice guidelines in oncology. Non-small cell lung cancer, Version 6; 2018. Available from: https://www.nccn. org/patients/guidelines/cancers.aspx\#nsclc. Accessed October 25, 2018.

16. Kawano D, Takeo S, Katsura M, Tsukamoto S, Masuyama E, Nakaji Y. Surgical treatment of stage IV non-small cell lung cancer. Interact Cardiovasc Thorac Surg. 2012;14(2):167-170.
17. Siddiqui F, Bae K, Langer CJ, et al. The influence of gender, race, and marital status on survival in lung cancer patients: analysis of Radiation Therapy Oncology Group trials. J Thorac Oncol. 2010;5(5):631-639.

18. Lo Russo G, Imbimbo M, Garassino MC. Is the chemotherapy era in advanced non-small cell lung cancer really over? Maybe not yet. Tumori. 2016;2016(3):223-225.

19. David EA, Canter RJ, Chen Y, Cooke DT, Cress RD. Surgical management of advanced non-small cell lung cancer is decreasing but is associated with improved survival. Ann Thorac Surg. 2016;102(4):1101-1109.

20. David EA, Clark JM, Cooke DT, Melnikow J, Kelly K, Canter RJ. The role of thoracic surgery in the therapeutic management of metastatic non-small cell lung cancer. J Thorac Oncol. 2017;12(11):1636-1645.

21. Abdel-Rahman O. Outcomes of surgery as part of the management of metastatic non-small-cell lung cancer: a Surveillance, Epidemiology and End Results database analysis. Cancer Invest. 2018;36(4):238-245.

22. Cai Y, Wang WL, Xu B, Zhu GY, Zhang SW. Survival status of stage IV non-small cell lung cancer patients after radiotherapy - a report of 287 cases. Ai Zheng. 2006;25(11):1419-1422.

23. Kogure Y, Ando M, Saka H, et al. Histology and smoking status predict survival of patients with advanced non-small-cell lung cancer. Results of West Japan Oncology Group (WJOG) Study 3906L. JThorac Oncol. 2013;8(6):753-758.

24. Goldstraw P, Chansky K, Crowley J, et al. The IASLC Lung Cancer Staging Project: proposals for revision of the TNM stage groupings in the forthcoming (eighth) edition of the TNM classification for lung cancer. J Thorac Oncol. 2016;11(1):39-51.

25. Noone AM, Lund JL, Mariotto A, et al. Comparison of SEER treatment data with medicare claims. Med Care. 2016;54(9):e55-e64. 


\section{Supplementary material}

Table SI Results of the univariable and multivariable Cox regression analysis before combining the subgroups with similar OS

\begin{tabular}{|c|c|c|c|}
\hline \multirow{2}{*}{$\begin{array}{l}\text { Demographic or clinicopathologic } \\
\text { characteristic }\end{array}$} & \multirow[t]{2}{*}{ Univariable analysis $P$} & \multicolumn{2}{|l|}{ Multivariable analysis } \\
\hline & & Hazard ratio $(95 \% \mathrm{Cl})$ & $P$ \\
\hline Sex & $<0.001$ & & $<0.001$ \\
\hline Female & & Reference & \\
\hline Male & & $1.168(1.128-1.210)$ & $<0.001$ \\
\hline Marital status & $<0.001$ & & $<0.001$ \\
\hline Married & & Reference & \\
\hline Unmarried & & $1.093(1.055-1.132)$ & $<0.001$ \\
\hline Race & $<0.001$ & & $<0.001$ \\
\hline White & & Reference & \\
\hline Black & & $0.949(0.90 \mathrm{I}-0.999)$ & 0.047 \\
\hline Others & & $0.682(0.639-0.727)$ & $<0.001$ \\
\hline Age at diagnosis, years & $<0.001$ & & $<0.001$ \\
\hline$\leq 61$ & & Reference & \\
\hline $62-73$ & & $1.152(1.108-1.198)$ & $<0.001$ \\
\hline$\geq 74$ & & $1.288(1.228-1.352)$ & $<0.001$ \\
\hline Histology & $<0.001$ & & $<0.001$ \\
\hline Adenocarcinoma & & Reference & \\
\hline Squamous cell cancer & & $1.260(1.200-1.312)$ & $<0.001$ \\
\hline Large cell cancer & & $1.157(1.037-1.290)$ & 0.009 \\
\hline Others & & $\mathrm{I} .172(\mathrm{I} . \mathrm{I} I 8, \mathrm{I} .229)$ & $<0.001$ \\
\hline Grade & $<0.001$ & & $<0.001$ \\
\hline $\mathrm{I}$ & & Reference & \\
\hline II & & $\mathrm{I} .027$ (0.888-I.I88) & 0.719 \\
\hline III & & $1.248(1.085-1.436)$ & 0.002 \\
\hline IV & & $1.486(1.206-1.829)$ & $<0.001$ \\
\hline Unknown & & 1.167 (1.017-1.339) & 0.028 \\
\hline T stage & $<0.001$ & & $<0.001$ \\
\hline T0, TI & & Reference & \\
\hline $\mathrm{T} 2$ & & $1.237(1.165-1.313)$ & $<0.001$ \\
\hline T3 & & $1.318(1.239-1.402)$ & $<0.001$ \\
\hline $\mathrm{T} 4$ & & $1.293(1.218-1.374)$ & $<0.001$ \\
\hline$T x$ & & $1.296(1.202-1.397)$ & $<0.001$ \\
\hline $\mathrm{N}$ stage & $<0.001$ & & $<0.001$ \\
\hline No & & Reference & \\
\hline $\mathrm{NI}$ & & $1.196(1.115-1.282)$ & $<0.001$ \\
\hline N2 & & $1.289(1.232-1.349)$ & $<0.001$ \\
\hline N3 & & $\mathrm{I} .405(\mathrm{I} .330-\mathrm{I} .485)$ & $<0.001$ \\
\hline $\mathrm{Nx}$ & & $\mathrm{I} .284(\mathrm{I} .168-\mathrm{I} .4 \mathrm{II})$ & $<0.001$ \\
\hline Primary Site & $<0.001$ & & 0.005 \\
\hline Main bronchus & & Reference & \\
\hline Lobe & & $0.882(0.8 \mid 4-0.956)$ & 0.002 \\
\hline Overlapping lesion & & $\mathrm{I} .040(0.860-1.259)$ & 0.683 \\
\hline Lung, NOS & & $0.902(0.822-0.989)$ & 0.029 \\
\hline Laterality & 0.821 & & \\
\hline \multicolumn{4}{|l|}{ Left } \\
\hline \multicolumn{4}{|l|}{ Right } \\
\hline \multicolumn{4}{|l|}{ Others } \\
\hline With Mla & $<0.001$ & & $<0.001$ \\
\hline No & & Reference & \\
\hline Yes & & $1.146(1.100-1.194)$ & $<0.001$ \\
\hline Bone metastasis & $<0.001$ & & $<0.001$ \\
\hline No & & Reference & \\
\hline Yes & & $\mathrm{I} .275(\mathrm{I} .22 \mathrm{I}-\mathrm{I} .33 \mathrm{I})$ & $<0.001$ \\
\hline
\end{tabular}


Table SI (Continued)

\begin{tabular}{|c|c|c|c|}
\hline \multirow{2}{*}{$\begin{array}{l}\text { Demographic or clinicopathologic } \\
\text { characteristic }\end{array}$} & \multirow[t]{2}{*}{ Univariable analysis $P$} & \multicolumn{2}{|l|}{ Multivariable analysis } \\
\hline & & Hazard ratio $(95 \% \mathrm{Cl})$ & $P$ \\
\hline Brain metastasis & $<0.001$ & & $<0.001$ \\
\hline No & & Reference & \\
\hline Yes & & $1.185(1.134-1.238)$ & $<0.001$ \\
\hline Liver metastasis & $<0.001$ & & $<0.001$ \\
\hline No & & Reference & \\
\hline Yes & & $1.339(1.283-1.397)$ & $<0.001$ \\
\hline Radiation & $<0.001$ & & 0.143 \\
\hline \multicolumn{4}{|l|}{ No } \\
\hline \multicolumn{4}{|l|}{ Yes } \\
\hline Chemotherapy & $<0.001$ & & $<0.001$ \\
\hline No/Unknown & & Reference & \\
\hline Yes & & $0.421(0.405-0.437)$ & $<0.001$ \\
\hline Surgery & $<0.001$ & & $<0.001$ \\
\hline No & & Reference & \\
\hline Yes & & $0.568(0.50 \mathrm{I}-0.642)$ & $<0.001$ \\
\hline
\end{tabular}

Abbreviation: OS, overall survival.

\section{Publish your work in this journal}

Cancer Management and Research is an international, peer-reviewed open access journal focusing on cancer research and the optimal use of preventative and integrated treatment interventions to achieve improved outcomes, enhanced survival and quality of life for the cancer patient. The manuscript management system is completely online and includes a very quick and fair peer-review system, which is all easy to use. Visit http://www.dovepress.com/testimonials.php to read real quotes from published authors. 